\title{
A New Learning and Fuzzy Strategy for Active Power Filtering
}

\author{
Hichem Laib ${ }^{1}$, Abd Elaziz Chaghi ${ }^{1}$ and Patrice Wira ${ }^{2}$ \\ ${ }^{1}$ Department of Electrical Engineering, LSPIE Laboratory, Batna University, Algeria, \\ ${ }^{2}$ MIPS Laboratory, University of Haute Alsace, Mulhouse, France \\ hichem_elt@yahoo.fr
}

\begin{abstract}
: in this paper, an enhanced control scheme is proposed to improve the performances of a three-phase shunt active power filter. The objective is to compensate for current harmonics and reactive power in three-phase power distribution grid. The proposed control scheme is inserted in the active filter in order to regulate the DC link capacitor voltage. This control scheme is based on the combination of a fuzzy logic controller and an ADALINE network (Adaptive FLC). The ADALINE is used to filter the measured DC voltage; an error is than calculated and with its derivative are injected in a fuzzy controller. The output of this controller is used to generate the compensating currents that are injected in the power distribution grid. The controller's outputs are combined with calculated reference currents. These are obtained for each phase with an ADALINE network which yields to a precise decomposition of the measured currents. Based on Fourier series, this neural approach provides in real time each individual harmonic component of the measured currents without any additional reference frame transforms. Simulation tests show that the proposed approach is able to significantly reduce the fluctuations of the DC voltage. The results also show that the proposed control approach can compensate for highly distorted line currents in a better way than with more traditional techniques.
\end{abstract}

Keywords: Neural Network, Fuzzy Logic Control, Active Power Filter, Power Quality.

\section{Introduction}

Nowadays there has been a rapid increase in the number of power electronic loads resulting in alarming levels of harmonic distortion in the distribution systems. These harmonics circulate in the electrical network, disturb the correct operation of the components and even it may damage them [1-2]. Shunt Active Power Filters (APFs) are recognized solutions to compensate for harmonic distortions, to correct the power factor and to recover the balance in power distribution systems by injecting compensating currents [3-4]. One important factor which influences the performance of the APFs is the speed and accuracy of the detection tool for the power line harmonic currents. APFs can be used with different control strategies. One of the most widely used is based on the conventional instantaneous power theory ( $p q$-method) initiated by Akagi [3]. This approach works in the $\alpha \beta$ reference frames, calculates the real and imaginary instantaneous powers and separates their alternative parts from their continuous parts. The alternative parts of the powers are then used to deduce the compensation currents. This principle has been efficiently achieved through neural approaches in [5-6-7]. The main drawbacks of the $p q$-method for identifying harmonic terms are essentially the following [8]:

It is not effective under distorted and unbalanced main voltage conditions.

The time delays introduced by pass filters, which are used to separate the average and oscillating parts of powers, degrades the dynamic performance of the active filter.

This method requires more computational calculation.

Recently, Artificial Neural Networks (ANNs) have been successfully applied to power systems [4]. With their learning capabilities, ANNs are able to take into account time-varying parameters [9-10]. Inserted in an APF scheme, they can appreciably improve its performance compared to the one obtained with traditional methods. Several methods have been proposed in [5] where ADALINE neural networks have been used to on-line learn the expressions of the signals, i.e., either instantaneous powers or currents. The ADALINE is a simple and fast adaptive scheme which is suitable for on-line applications [11].

Received: October $14^{\text {th }}, 2015$. Accepted: August $23^{\text {rd }}, 2016$ 
In this paper, a neural network and a fuzzy logic approach are proposed to enhance the performances of an APF. The adaptive neural network is used in an open-loop and extracts with high precision the fundamental components of the distorted line currents directly from the $a b c$ axis. The output of the ADALINE is compared with distorted supply current to obtain the reference current. The Adaptive Fuzzy Logic Controller (Adaptive FLC) is used in a closedloop to maintain the DC-bus voltage constant at the reference value and minimize the fluctuations in the DC bus voltage [1-2]. The output of the closed-loop and the open-loop is summed to construct the modulating signals as shown by Figure. 1. These modulating signals are used to generate the Pulse-Width Modulation (PWM) pulses to be fed into the APF in order to generate the compensating currents. This allows maintaining the electrical power to be in a good shape when transported to end-users.

\section{Proposed Control Approach}

The schematic diagram of the proposed control approach for a shunt APF is shown in figureure.1. Where, the main function of the controller is to create the PWM switching signals for the connected Voltage Source Inverter (VSI).

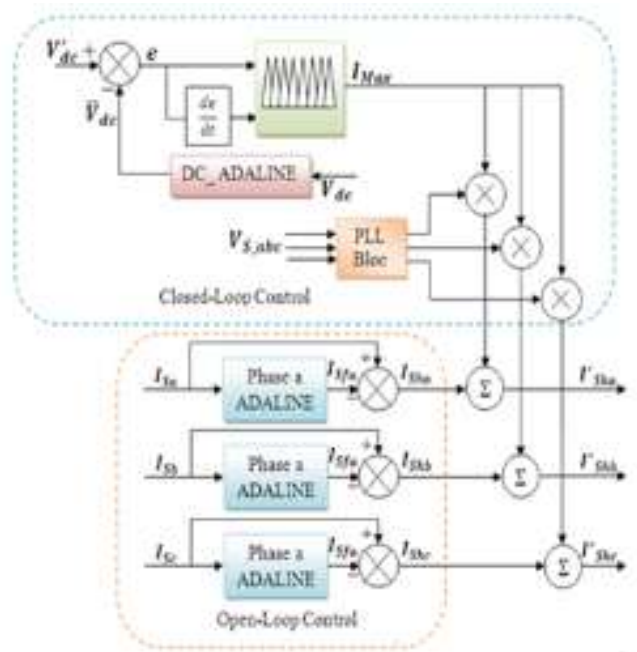

Figureure 1. The proposed approach control

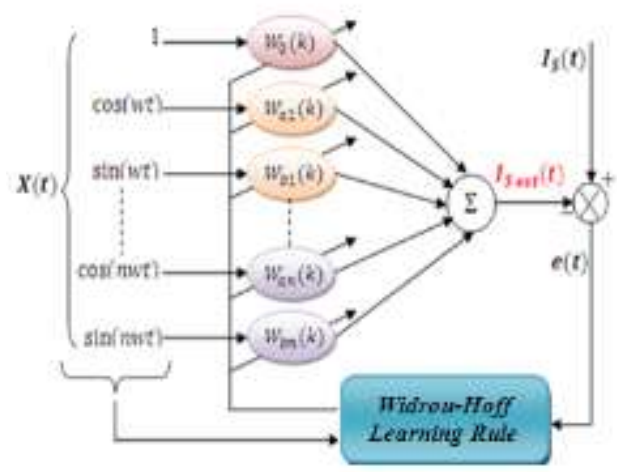

Figure 2. The ADALINE network

Our proposed control system consists of two control loops, an open and a closed loop. In the open loop, the signal containing the harmonics, $I_{s h}$, is obtained from the output of the 
ADALINE and then its value is summed by $-V_{s} * I_{\text {Max }}$. The output of the FLC, $I_{\text {Max }}$, is used to maintain the DC-side voltage at its reference value. The opposite of this signal is used as a current reference signal. The sum of the open loop control signal and the closed-loop control signal is used as a modulating signal for each of the three phases. The PWM control strategy then uses them to create the PWM switching pattern for driving the switches of the power converter.

In the next section, we describe the ADALINE approach and more specifically the direct method and the design of the FLC applied to the APF system.

\section{ADALINE as Harmonic Estimator}

The ADALINE network is used in order to identify the current harmonics [15]. In our application, this is achieved according to the direct method which means that the ADALINE works directly the space of the measured current of the electrical supply network. So, three ADALINE networks must be used for the three phases of an electrical supply network. Each one can be decomposed into Fourier series in the following way [14-15]:

$$
\begin{gathered}
I_{S}(t)=I_{s f}(t)+I_{s h}(t) \\
I_{S}(t)=I_{11} \cos (w t-\alpha)+I_{12} \sin (w t-\alpha)+\sum_{n=2}^{\infty} I_{1 n} \cos \mathrm{n}(w t-\alpha)+I_{2 n} \sin \mathrm{n}(w t-\alpha)
\end{gathered}
$$

In this expression, $I_{s}$ represents the current source, $I_{s f}$ is the fundamental component of current source and $I_{s h}$ is the harmonics current. Currents $I_{s f}$ and $I_{s h}$ can be expressed by:

$$
\begin{aligned}
& I_{s f}(t)= \\
& I_{11} \cos (w t-\alpha)+I_{12} \sin (w t-\alpha) \\
& I_{s h}= \\
& \sum_{n=2}^{\infty} I_{n 1} \cos \mathrm{n}(w t-\alpha)+ \\
& I_{n 2} \sin \mathrm{n}(w t-\alpha)
\end{aligned}
$$

In the previous expressions, $w$ is the fundamental frequency, $\alpha$ is the phase shift between the current and the load voltage, $I_{11}$ and $I_{12}$ are the cosine and sine frequency components of the fundamental current, $I_{n 1}$ and $I_{n 2}$ are the cosine and sine frequency components of the harmonics current. The identification of the harmonics components is achieved with an ADALINE for each phase [14-15]. This is shown by Figure. 2.

The expression of the current expressed in (1) can be written as a linear combination which can be learned by an ADALINE network:

$$
I_{h}(t)=W^{T} x(t)
$$

Where $x(t)$ is the network input vector and $W^{T}$ is the ADALINE weight vector. The input vector is chosen as follow:

$$
x(t)=[\cos (w t-\alpha) \sin (w t-\alpha) \ldots \cos . n(w t-\alpha) \sin . n(w t-\alpha)]
$$

The weight adjustment, or adaptation, is performed during the training process of the ADALINE using a nonlinear adaptation algorithm.

In order to update the weight vector and minimize the mean square error between the desired signal output $y_{d}(t)$ and the estimate output $y_{\text {est }}(t)$, the Widrow-Hoff learning delta rule is used [11-12-13]:

$$
w(k+1)=w(k)+\mu \frac{e(k) * X(K)}{X^{T}(k) * X(k)}
$$


This expression uses the following parameters:

$k$ is the time index of iteration,

$\mathrm{w}(\mathrm{k})$ is the weight vector at time $\mathrm{k}$,

$\mathrm{X}(\mathrm{k})$ is the input vector at time $\mathrm{k}$,

$e(k)=y_{d}(t)-y_{e s t}(t)$, is the error at time $\mathrm{k}$,

$\mu$ Represents the learning rate of the weight update law.

Then, after learning and convergence, the weights of the ADALINE correspond to

$$
\left[\begin{array}{llllll}
W^{T}=I_{11} & I_{12} & \ldots & \ldots & I_{n 1} & I_{n 2}
\end{array}\right]
$$

The amplitude of continuous component of the fundamental current will be determined by the weight $W_{0}(k)$ of a first neural network ADALINE multiplying by $\cos (w t)$ and $\sin (w t)$ as follows [13]:

$$
I_{s f}=I_{11} \cos (w t)+I_{12} \sin (w t)
$$

Once the fundamental current is determined, the harmonic current can be obtained by subtracting the fundamental component of current estimated by the ADALINE from the measured current. This can be expressed by:

$$
I_{s h}(t)=I_{s}(t)-I_{s f}(t)
$$

This harmonic current $I_{s h}(t)$ for one phase will then be injected phase-opposite in the electrical network via a controlled device, i.e., the VSI.

\section{Design of DC-Bus Controller}

The DC capacitor voltage must be maintained at a desired value, to compensate the losses in the active filter. The voltage control of the DC bus is achieved by adjusting a small amount of the real power flowing into the DC capacitor. Several methods are used like PI, PID, RST or FLC controllers. In our application, we utilize a novel approach contain a Fuzzy logic controller including another Adaptive Linear Neural Network (ADALINE) algorithm.

The first controller (FLC) is practically used to maintain the DC capacitor voltage at a reference value and the second estimator (DC_ADALINE) used to minimize the voltage fluctuations; this approach is used in a closed loop.

So, the DC-bus capacitor voltage is sensed and then passes through DC_ADALINE to filter the higher voltage fluctuations and passes only the fundamental component, then this component $\left(\bar{V}_{d c}\right)$ is compared with a desired reference value. The error signal $e(t)$ and a variation of it given by $\Delta e(t)=e(t)-e(t-1)$ are used as the inputs of the FLC as shown in Figure. 3 [1-2]. The output of the fuzzy controller estimates the magnitude of the peak reference current $I_{\text {Max }}$. This current takes into account the active power demand of the nonlinear load for harmonics and reactive power compensation. This peak reference current is then multiplied with the system voltage $\left(-V_{s . a b c}\right)$ to output a synchronized reference current as shown by Figure. 1. These are: NL (negative big), NM (negative medium), NS (negative small), Z (zero), PS (positive small), PM (positive medium), and PB (positive big) [1-2-22-2324-25]. The seven fuzzy sets are for each input $(e, \Delta e)$ and for the output $I_{\text {Max }}$ with triangular and trapezoidal membership functions with are characterized by:

- Fuzzification step using a continuous universe of discourse;

- an implication using Mamdani’s 'min' operator;

- a defuzzification step using the 'centroid' method.

The membership functions used for the input and output variables used here are shown by Figure 4. As both inputs have seven subsets, a fuzzy rule base formulated for the present application is provide by Table 1 . 
In order to convert the real values into linguistic variables, we use seven fuzzy sets.

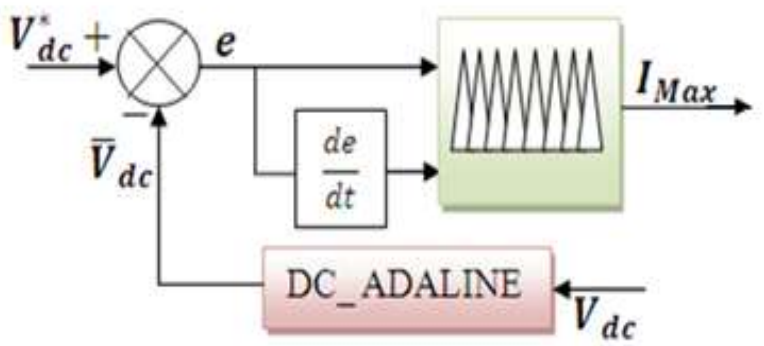

Figure 3. The Adaptive Fuzzy Logic Controller strategy

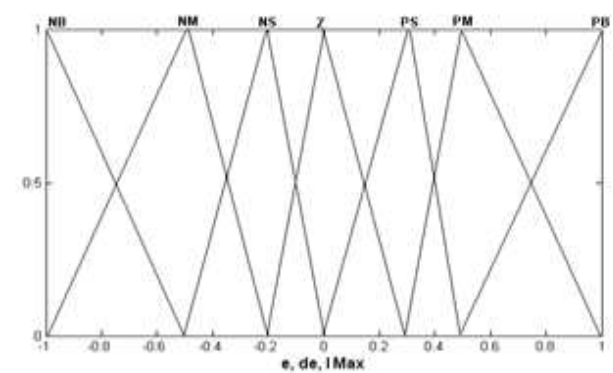

Figure 4. Membership functions for the inputs and output variables

Table 1. The fuzzy sets for the design of the FLC

\begin{tabular}{|c|c|c|c|c|c|c|c|}
\hline $\mathrm{e}$ & $\mathrm{NL}$ & $\mathrm{NM}$ & $\mathrm{NS}$ & ZE & PS & PM & PL \\
\hline NL & NL & NL & NL & NL & NM & NS & ZE \\
\hline NM & NL & NL & NL & NM & NS & ZE & PS \\
\hline NS & NL & NL & NM & NS & ZE & PS & PM \\
\hline ZE & NL & NM & NS & ZE & PS & PM & PL \\
\hline PS & NM & NS & ZE & PS & PM & PL & PL \\
\hline PM & NS & ZE & PS & PM & PL & PL & PL \\
\hline PL & NL & NM & NS & ZE & PS & PM & PL \\
\hline
\end{tabular}

\section{Simulations and Analysis of The Results}

In order to evaluate our compensation approach based on ADALINE and a Fuzzy logic controller including another ADALINE, a digital simulation is carried out. This study examines an electrical distribution networks having an unbalanced three-phase voltage source, a nonlinear load that generates a high level of harmonics and a shunt APF to compensate for them. Figure 5 shows the electrical scheme of the system and the values of the main parameters are given in Table 2.

Obviously, the proposed control scheme must be evaluated under changing and varying conditions. Thus, the nonlinear load is changed at $t=0.125 \mathrm{~s}$ and the converter is set up with a firing angle of $20^{\circ} 20^{\circ}$.

The performances of the proposed approach are given by figure 6 , figure 7 and figure 8 . The steady state and transient behaviors of the controlled system can be seen. Figure 6 shows the load current without compensation with its harmonic spectrum, and the source currents 
with its harmonic spectrum after compensation is depicted in figure 7, figure 8 shows for one phase, a) the measured and estimate load current bay the ADALINE Estimator, b) the first weight $\mathrm{W}_{0}$ where it represent the amplitude of the fundament current, c) the compensating current issued by the APF, d) the resulting source current and source voltage, and e) the DC capacitor voltage. The overall performance of the compensating strategy can be seen with the active and reactive powers on the source side. They are represented by figure $8 \mathrm{f}$, and can be compared to the one on the nonlinear load side without compensation.

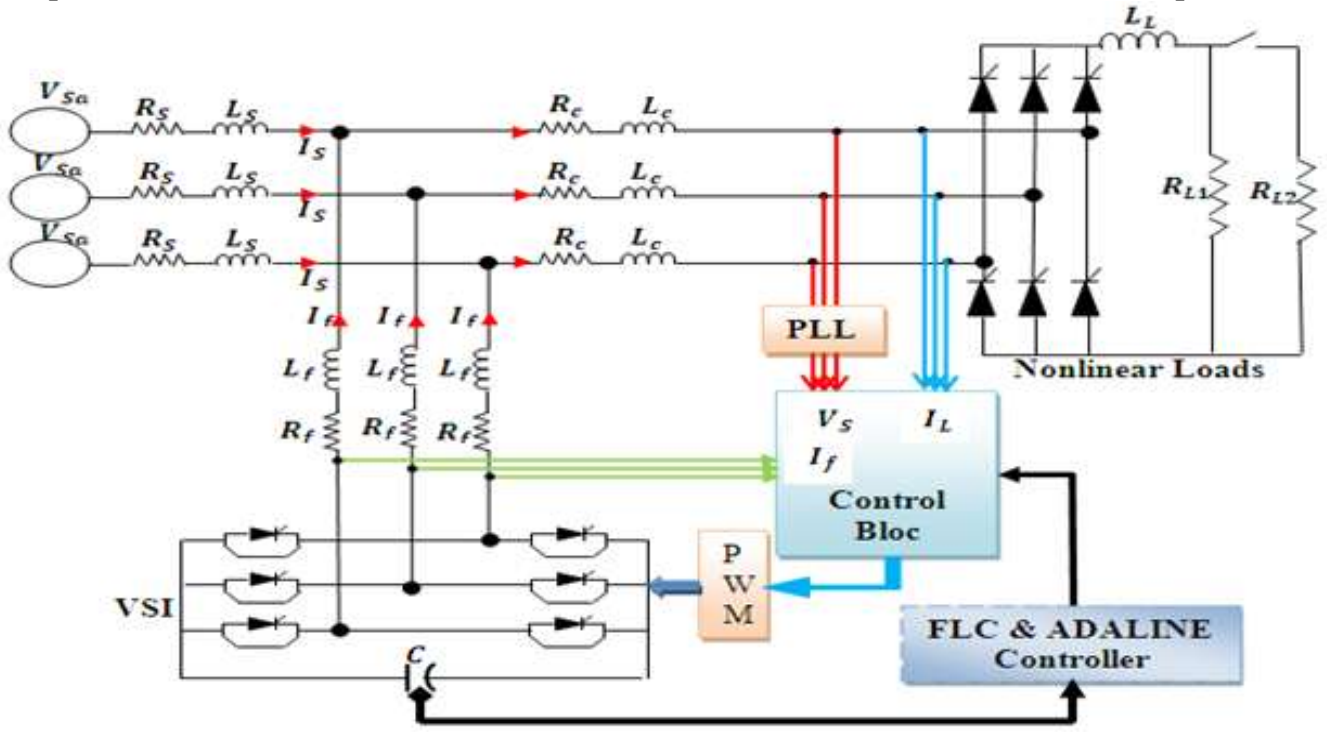

Figure 5. Overall scheme of the compensation strategy based on a shunt APF inserted in the electrical distribution network

Table 2. VALUES OF THE ELECTRICAL PARAMETERS

\begin{tabular}{||l|c||}
\hline $\begin{array}{l}\text { PHASE TO NEUTRAL } \\
\text { SOURCE VOLTAGE }\end{array}$ & $V_{s a}=250 \sqrt{2}, V_{s b}=230 \sqrt{2}, V_{s c} 270 \sqrt{2}$ \\
\hline System Frequency & $f=50 \mathrm{~Hz}$ \\
\hline Source impedance & $R_{S}=3.5 \mathrm{~m} \Omega, L_{s}=0.05 \mu \mathrm{H}$ \\
\hline Filter impedance & $R_{C}=0.82 \mathrm{~m} \Omega, L_{C}=0.1 \mathrm{mH}$ \\
\hline Load impedance & $R_{L 1}=1.5 \Omega, R_{L 2}=3 \Omega, L_{L}=6 \mathrm{mH}$ \\
\hline DC side capacitance & $C=8 \mathrm{mF}$ \\
\hline DC-bus voltage reference & $V_{d c}^{*}=850 \mathrm{~V}$ \\
\hline
\end{tabular}



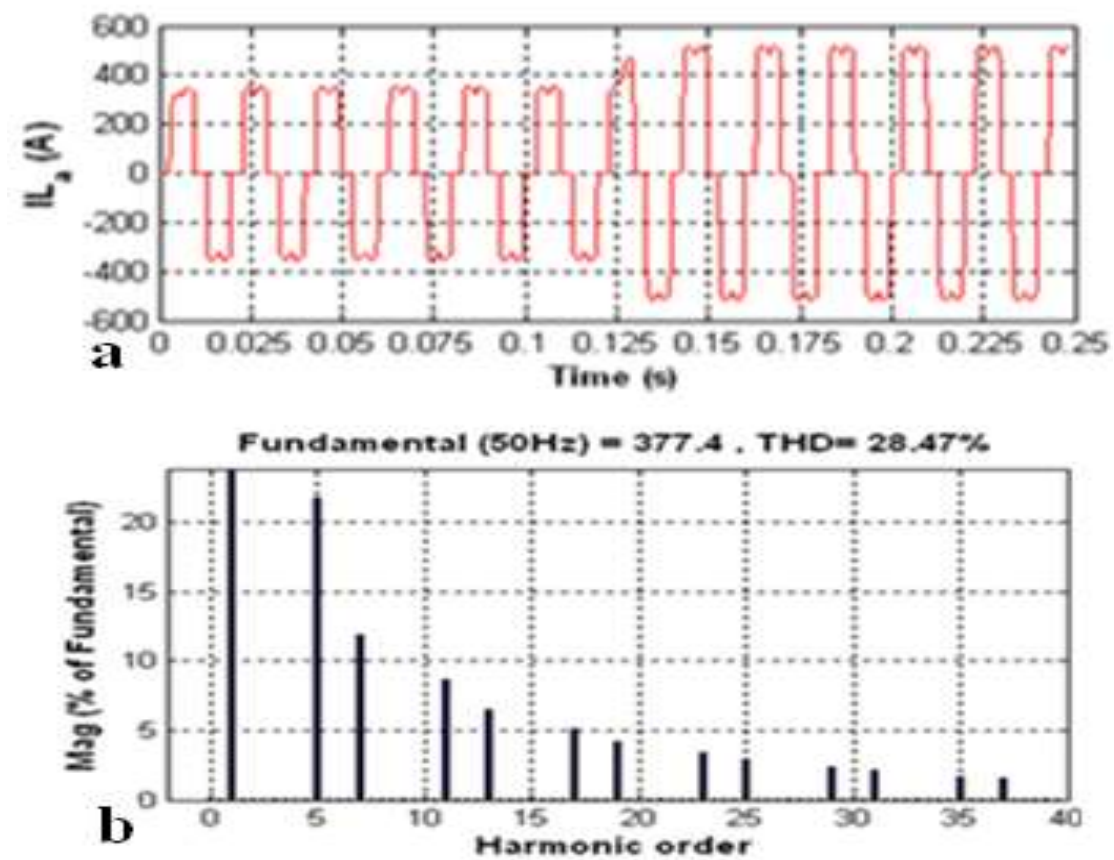

Figure 6. Load currents and its harmonics spectrum before compensation (THD=28\%)

Figure 6 and 7 shows the Load currents and its harmonics spectrum before and after compensation where the THD has been reduced from $28.47 \%$ without compensation to $1.23 \%$ with the compensation strategy. It can be seen from the previous figure that the propose compensation technique of the APF is able to reduce the harmonics generated by the nonlinear load. Indeed, the resulting currents are sinusoidal and in phase with the source voltages, even under nonlinear load changes. The Total Harmonic Distortion (THD) rate and the Power Factor (PF) have been recorded. Finally, by using the ADALINE as an estimator of the current harmonics, it can be seen from the figure 8 that this technique gives good results,
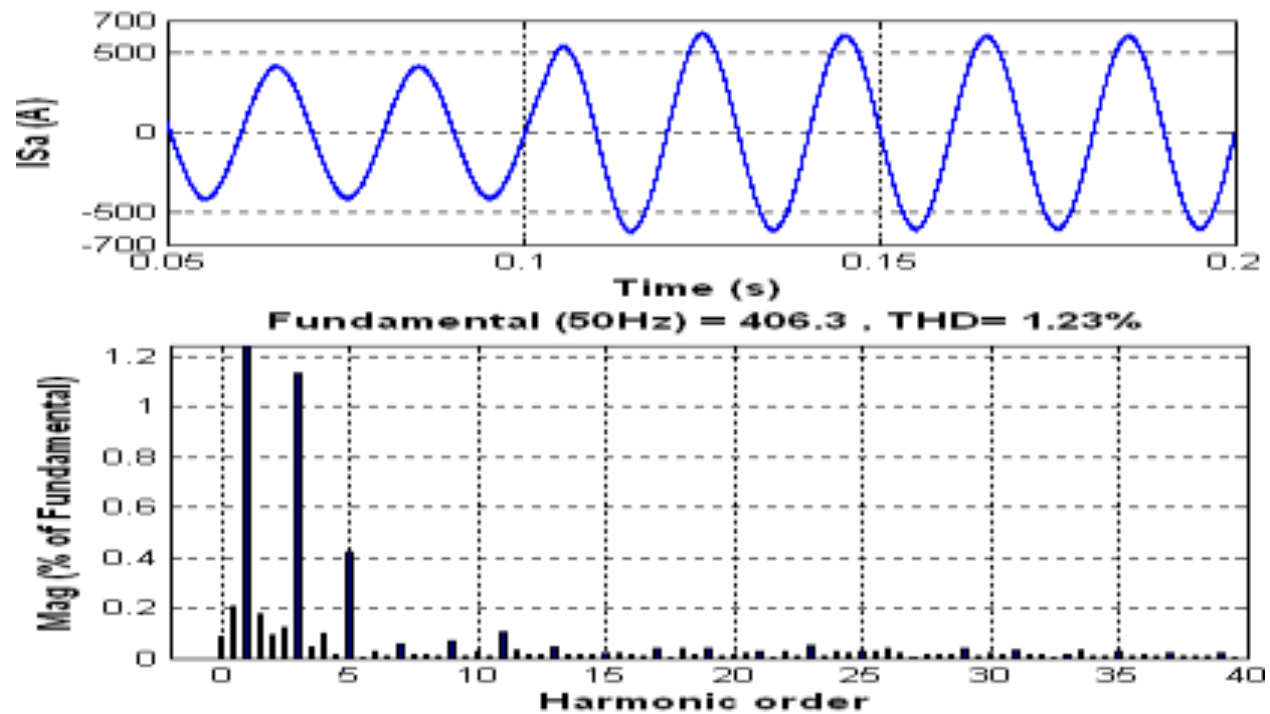

Figure 7. Load currents and its harmonics spectrum after compensation (THD=1.23\%) 

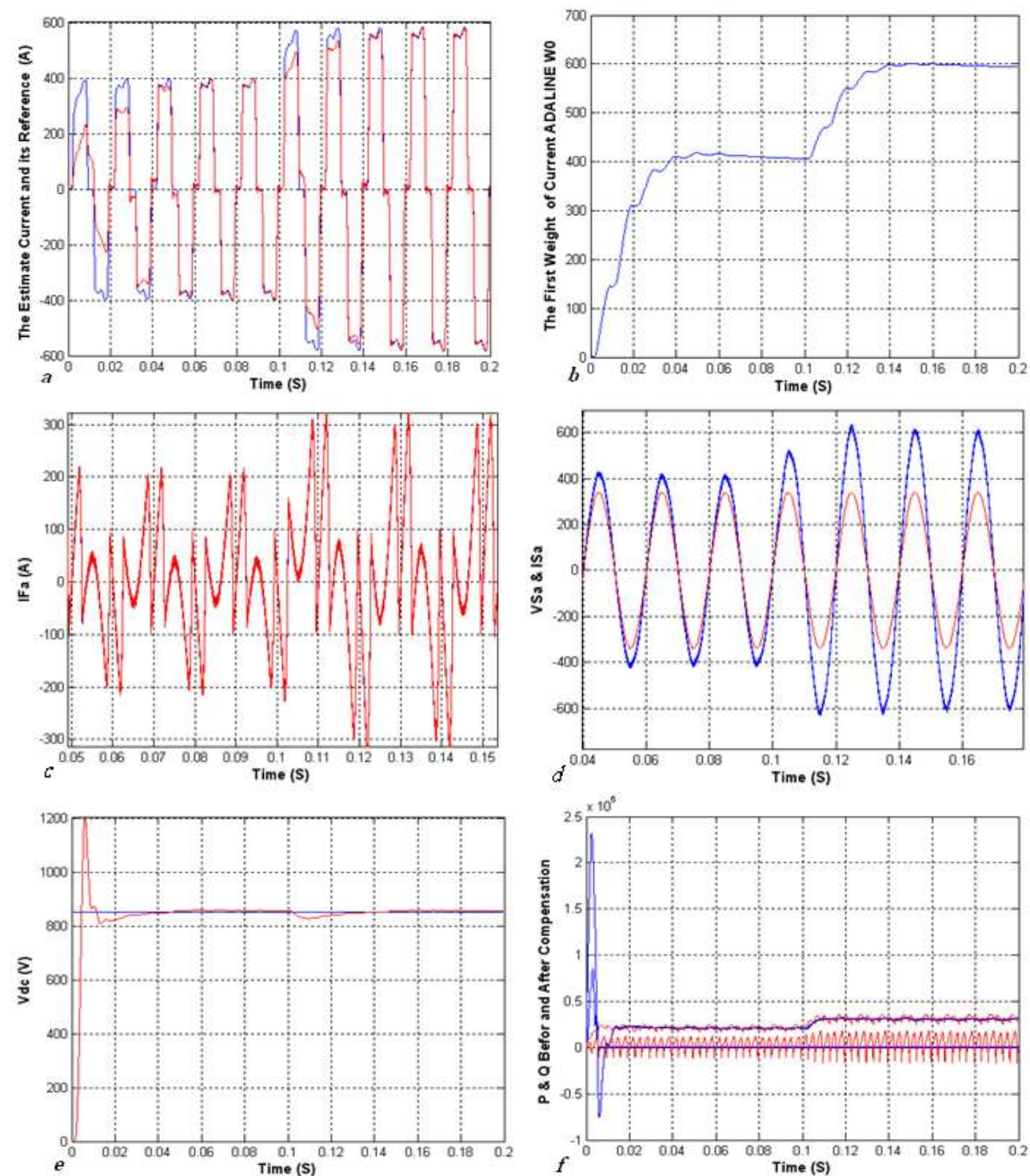

Figure 8. Simulation results, a) the load current and its estimation bay ADLINE algorithm b) the first weight $\mathrm{w}_{0} \mathrm{c}$ ) reference and compensation currents from the APF, d) voltage and current source waveforms before compensation, e) the DC capacitor voltage.

By using the FLC including an ADALINE in a closed-loop control, the DC-bus voltage is maintained at the desired value, when the nonlinear load changes. The fluctuation and transient response is also excellent. This can be observed from figure 8 where the active and reactive powers fast evolutions are depicted. The reactive power is almost cancelled. The real power from the $\mathrm{AC}$ source side is practically free of the alternating part due to the nonlinear property of the load.

\section{Conclusion}

Practically a shunt active power filter has been used to compensate for harmonics and reactive power produced by the nonlinear load inserted in a power distribution grid.

In this paper the identification of the harmonic currents is achieved by an adaptive neural network approach. The ADALINE is made directly in the measured current frame. This is 
called the direct method. In order to maintain the DC voltage at the desired value the adaptive fuzzy logic controller (adaptive FLC) is used in closed loop, where it will be also able to minimize the DC voltage fluctuations and the settling time.

The effectiveness of the approach has been illustrated by the simulation results with the Matlab/Simulink toolbox Power System.

The results show that the proposed control approach can compensate for highly distorted line currents by generating and injecting appropriate compensation currents. In the various test cases simulated with different nonlinear loads, the THD of the supply current is always reduced to a value which is less than $5 \%$. The performances obtained by the proposed method are better than those obtained by more traditional techniques.

In future work we plan to expand the use of artificial neural networks. We will intend to use other active compensation schemes and generalize their control strategies.

\section{References}

[1]. Laib, Hichem., Kouara, Hanane., Chaghi, Abd Elaziz., “A New Approach of Modular Active Power filtering”. International Journal of Advanced Science and Technology, Vol. 50, January, 2013.

[2]. Laib, Hichem., Kouara, hanane., Chaghi, Abd Elaziz., "An Advanced Control Approach for Modular Active Power Filtering". ACTA Technica Corviniensis - Bulletin of Engineering, Tome VI (year 2013) - Fascicule 2 [April- June], ISSN 2067- 3809.

[3]. Akagi, H., Watanabe, E.H., Aredes, M., "Instantaneous Power Theory and Applications to Power Conditioning". Wiley-IEEE Press. 2007.

[4]. Nguyen, N. K., Wira, P., Flieller, D., Oul Abdeslam., Mercklé, J., "A Comparative Experimental Study of Neural and Conventional Controllers for an Active Power Filter". 36th An. Conf. of the IEEE Industrial Electronics Society (IECON10), 2010.

[5]. Ould Abdeslam, D., Wira, P., Mercklé, J., Flieller, D., Chapuis, Y.-A., "A Unified Artificial Neural Network Architecture for Active Power Filters". IEEE Trans. on Industrial Electronics, Vol. 54, No. 1, pp. 61-76, 2007.

[6]. Flieller, D., Ould Abdeslam, D., Wira, P., Merckl'e, J., "Distortions identification and compensation based on artificial neural networks using symmetrical components of the voltages and the currents". Electric Power Systems Research. Vol. 79, No. 7, pp. 11451154, 2009.

[7]. Nguyen, N.K., Flieller, D., Wira, P., Ould Abdeslam, D., Merckl'e, J., "Neural networks for phase and symmetrical components estimations in power systems". 35th An. Conf. of the IEEE Industrial Electronics Society (IECON09), 2009.

[8]. Lamchich, M. T., "ANN current controller based on PI-Fuzzy adaptive system for shunt power active filter". Advances in Power Electronics Volume 2012, Article ID 237259. 6 pages.

[9]. Vazquez, J., Salmeron, P., "Active power filter control using neural network technologies". IEE Proceedings - Electric Power Applications. vol. 150, no. 2, pp. 139$145,2003$.

[10]. Ould Abdeslam, D., Mercklé, J., Ngwanyi. R., Chapuis, Y.A., "Artificial Neural Networks for Harmonic Estimation in Low-Voltage Power Systems". Fourth International ICSC Symposium on Engineering of Intelligent Systems (EIS 2004), Island of Madeira, Portugal, 2004.

[11]. Widrow, B., Lehr, M.A.:30 years of adaptive neural networks, "Perceptron, Madaline and Back propagation". Proceedings of the IEEE, Vol. 78, No.9, Sep, 1990, pp. 1415-1442.

[12]. Chandra Sekaran, E., Anbalagan, P., "Comparison of Neural Network and Fast Fourier Transform Based Selective Harmonic Extraction and Total Harmonic Reduction for Power Electronic Converter". Asian Power Electronics Journal, Vol. 2, No. 1, Apr 2008.

[13]. Ould Abdeslam, D., Mercklé, J., Wira, P., Flieller, D., "Harmonic Identification Based on ANN: A Comparative Study". 9th International Conference on Engineering Applications of Neural Networks-(EANN'2005), Lille, France, Aug. 24-26, 2005. 
[14]. Ould Abdeslam, Djafar., Techniques neuromimétiques pour la commande dans les systèmes électriques: application au filtrage actif parallèle dans les réseaux électriques basse tension . Thèse de doctorat. Université de Haute-Alsace, Mulhouse, 2005.

[15]. EL Shatshat, R. A., "A Novel Modular Approach to Active Power-Line Harmonic Filtering in Distribution Systems". Thèse de doctorat. Université de Waterloo, Ontario, 2001.

[16]. Narasa Reddy, T. M., Subramanyam, V., "Fuzzy Logic Controlled Shunt Active Power Filter for Mitigation of Harmonics with Different Membership Functions". International Conference on Advances in Computing, Control, and Telecommunication Technologies, 2009.

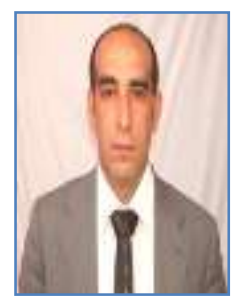

Hichem Laib, was born in Batna, Algeria, on may 05, 1980. He received his engineering and M.SC degree in Electrical Engineering, all from University of Batna, Algeria in 2005 and 2009 respectively. He is Ph.D Student in Electrical Engineering, in the same University. He is also member for the research team of "Power Quality in Distribution Power Systems" at LSP-IE research Laboratory at University of Batna and his work concerns Artificial Neural Networks specially ADALINE, Active Power Filters, FACTS Devises and Power Electronics.

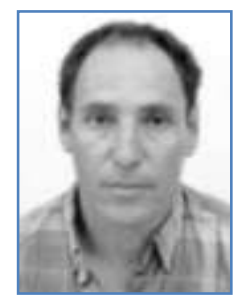

Abd Elaziz Chaghi, Professor in the Department of Electrical Engineering, University of Batna, Algeria. He received his engineering degree from the University of Oran, Algeria in 1980, and M.SC from Manchester University, United Kingdom (UK) in 1984. He received Doctor Degree in Power Systems from Batna University, Algeria in 2004. He is also responsible for the research team of "Power Quality in Distribution Power Systems" at LSPIE research Laboratory at University of Batna, Algeria. Professor Chaghi has published more than 50 papers in reputable international journals and conferences. His research interests include Power Systems Optimization, Power Electronics, Renewable Energy, Harmonics, Power Flow, Voltage Stability and FACTS Devises.

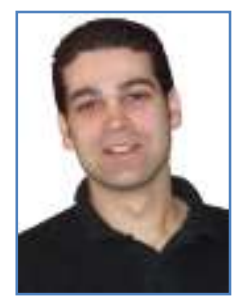

Patrice Wira obtained the Ph.D. degree in 2002 in automatic control and signal processing from the University of Haute Alsace (UHA), Mulhouse, France. He received the French habilitation to supervise research activities in 2009 from the UHA. Since 2011 he is a Full Professor. His current research interests are artificial neural networks for modeling and control, signal processing, intelligent control, control of electrical systems, active filtering, current harmonic compensation, And power quality. He has guided several projects in the areas of computational intelligence and smart grids. He is author of over 80 papers published in international journals, conferences and books. He is IEEE Senior Member. 